\title{
Demotivating factors influencing rubber production workers
}

\author{
Mohammad Reza Iravani*
}

Department of Social Work, Islamic Azad University of Khomeinishahr, Khomeinishahr Branch, Daneshjou Blvd, Iran

\begin{tabular}{|c|c|}
\hline A R T I C L E I N F O & A B S T RACT \\
\hline $\begin{array}{l}\text { Article history: } \\
\text { Received June 15, } 2011 \\
\text { Received in Revised form } \\
\text { August, 22, } 2011 \\
\text { Accepted } 25 \text { August } 2011 \\
\text { Available online } \\
\text { 26 August } 2011 \\
\text { Keywords: } \\
\text { Motivation } \\
\text { Worker skills }\end{array}$ & $\begin{array}{l}\text { Motivation is one of the most important factors influencing workers' productivity. An increase } \\
\text { in workers' motivation could add more value to organizations' structure and influence the } \\
\text { profitability, significantly. In this paper, we study different factors on demotivating workers } \\
\text { using questionnaire consist of various questions. The questionnaire is distributed among some } \\
\text { employees who work for rubber production units located in Esfahan, Iran. The results of this } \\
\text { survey indicate that discrimination on annual job compensation, entrusting responsibilities and } \\
\text { unpleasant relationship with family partner are some of the most important factors influencing } \\
\text { employees' motivation. While financial factors play important role on increasing employees' } \\
\text { motivation, non-financial factors are considered more important. }\end{array}$ \\
\hline
\end{tabular}

Productivity

Efficiency

\section{Introduction}

Motivation plays an important role on increasing firms' productivity and profitability. There have been virtually tremendous efforts on increasing workers' motivation through providing promotion programs, entertainment, salary hike, etc. There are, however, several hidden factors influencing workers' motivation, which need to be determined. A comprehensive study on detecting such factors could help managers reduce their influences using different techniques (Opsahl \& Dunnette 1996; Gällstedt , 2003; Tremblay et al., 2009). NG et al. (2004) investigated negative factors influencing the productivity of civil engineering projects. They improved worker productivity by identifying factors demotivating factors by indentifying the factors through an empirical survey in Hong Kong. The results of their survey indicated that time losses due to demotivation to be as much as 13.6 manhours/week, with material availability, overcrowded work areas and rework being the most significant demotivators involved.

Delfgaauw and Dur (2007) provided a method for signaling and screening of workers' motivation. In their work, they developed a model in which workers are heterogeneous in their intrinsic motivation to work at a factory. They characterized optimal incentive schemes and examined how the firm could attract and select highly motivated workers to fill a vacancy when workers' motivation was private

* Corresponding author. Tel: + 989131943910

E-mail addresses: iravani@iaukhsh.ac.ir (M. R. Iravani) 
information. They reported that although higher wage increases the likelihood of filling the vacancy, it decreases the expected average quality of job applicants because less motivated workers were induced to apply.

De Lange et al. (2010) proposed a method for dominant achievement goals of older workers and their relationship with motivation-related outcomes. They concentrated on older employees' achievement motivation by studying the prevalence of dominant achievement goals among a "unique" group of 172 Dutch workers who remained active after their post-statutory retirement age. In addition, they studied how their dominant achievement goals were linked to motivation-related outcomes such as work engagement and meaning of work. They reported that, relative to younger workers, a significantly higher amount of older workers endorsed dominant mastery-avoidance goals. In addition, older workers with dominant mastery-approach objectives scored highest, while the workers with dominant mastery-avoidance goals scored lowest in work engagement, social and personal meaning of work. Linz analyzed the difference between age and gender among Russian workers by proposing two hypotheses. First, Linz found that worker motivation would be positively correlated with organizational commitment, where organizational commitment was captured by a series of statements associated with the employee's perception of their workplace and the satisfaction expressed about the workplace and job. Second, Linz reported that worker motivation was positively correlated to the expectation that a desired reward would be received in exchange for doing the job well.

Lan et al. (2010) presented an empirical study for evaluating the effects of air temperature on office workers' well-being, workload and productivity with subjective ratings. They reported that the warm discomfort negatively affected participants' well-being and increased the ratio of low frequency (LF) to high frequency (HF) of HRV. In the moderately uncomfortable environment, the workload imposed by tasks increased and participants had to exert more effort to maintain their performance and they also had lower motivation to do work. Mak and Sockel (2001) presented a confirmatory factor analysis of IS employee motivation and retention. They investigated IS employees' motivation and intent to remain using structural equation modeling. They showed that latent motivation has an impact on latent retention, with job satisfaction and perceptions of management on career development as indicator variables for the former, and burnout, loyalty, and turnover intent as indicator variables for the latter through a survey conducted among existing IS employees.

Zakeri et al. (1997) studied factors affecting the motivation of Iranian construction operatives. They reported that the four most important motivation factors of Iranian construction operatives are, in descending order: "fairness of pay", "incentive and financial rewards", "on-time payment" and "good working facilities" and suggested that construction managers would have to be sensitive to these factors in order to sustain the drive for higher construction productivity.

In this paper, we present an empirical study to assess the negative factors influencing motivation on people who work for rubber industry. The present study designs a questionnaire, which consist of various questions and distributed among employees. The responses were gathered and analyzed to detect the important factors. This paper is organized as follows. We first present the organization of this paper first presents the structure of the survey in section 2 and details of the results are given in section 3. Finally, concluding remarks are given in the last section to summarize the contribution of this paper.

\section{Problem statement}

The proposed model of this paper uses Likert (1932) based scale from one to five to receive feedback from 20 despondences who participated in our survey. Table 1 shows details of some of the most important questions along with the frequencies and percentages of the despondences. 
Table 1

Feedback responses from despondences in terms of frequency and percentage

\begin{tabular}{lcccccccc}
\hline & \multicolumn{2}{c}{ Very little- } & \multicolumn{2}{c}{ Medium } & \multicolumn{2}{c}{ Much-Very much } & Weighted \\
\cline { 2 - 8 } Question & Freq. & $\%$ & Freq. & $\%$ & Freq. & $\%$ & Mean \\
\hline $\begin{array}{l}\text { How much does the lack of brightness affect your } \\
\text { performance? }\end{array}$ & 1 & 5 & 5 & 25 & 14 & 75 & 3.90 \\
$\begin{array}{l}\text { How much personal financial problem does it affect } \\
\text { your performance? }\end{array}$ & 3 & 15 & 4 & 20 & 13 & 65 & 3.75 \\
$\begin{array}{l}\text { How much lack of personal equipments does it affect } \\
\text { your performance? }\end{array}$ & 0 & 0 & 3 & 15 & 17 & 85 & 4.27 \\
$\begin{array}{l}\text { How much unpaid annual profit share could it affect } \\
\text { your performance? }\end{array}$ & 7 & 35 & 8 & 40 & 5 & 25 & 2.8 \\
\hline
\end{tabular}

In Table 1, the response along with weighted mean is shown for each question. As we can observe from Table 1, the lack of personal equipment with $85 \%$ plays the most important role on people's performance and the annual reward has the least impacting factor on the performance of employees. Table 2 explains other relative questions along with responses in Likert based.

Table 2

Feedback responses from despondences in terms of frequency and percentage on how much each of the following impact employee performance

\begin{tabular}{|c|c|c|c|c|c|c|c|}
\hline \multirow[b]{2}{*}{ Question } & \multicolumn{2}{|c|}{$\begin{array}{l}\text { Very little- } \\
\text { Little }\end{array}$} & \multicolumn{2}{|c|}{ Medium } & \multicolumn{2}{|c|}{ Much-Very much } & \multirow{2}{*}{$\begin{array}{l}\text { Weighted } \\
\text { Mean }\end{array}$} \\
\hline & Freq. & $\%$ & Freq. & $\%$ & Freq. & $\%$ & \\
\hline Unpleasant working conditions & 1 & 5 & 4 & 20 & 15 & 75 & 4.05 \\
\hline Uncomfortable working conditions & 9 & 45 & 2 & 10 & 9 & 45 & 3 \\
\hline Lack of job promotion & 0 & 0 & 10 & 50 & 10 & 50 & 3.75 \\
\hline Lack of appreciation & 4 & 20 & 5 & 25 & 11 & 55 & 3.52 \\
\hline Lack of perception of the managers & 2 & 10 & 9 & 45 & 9 & 45 & 3.52 \\
\hline Discrimination on annual compensation & 2 & 10 & 6 & 30 & 12 & 60 & 4.32 \\
\hline Paying no attention on personal characteristics & 5 & 25 & 7 & 35 & 8 & 40 & 3.22 \\
\hline No change on working conditions & 4 & 20 & 7 & 35 & 9 & 45 & 3.37 \\
\hline Long period of sickness & 9 & 45 & 2 & 10 & 6 & 45 & 3.00 \\
\hline Unclear working responsibilities & 1 & 5 & 5 & 25 & 14 & 70 & 3.97 \\
\hline Dishonest management & 8 & 40 & 6 & 30 & 6 & 30 & 2.85 \\
\hline No agreement for decisions to be made & 2 & 10 & 7 & 35 & 11 & 55 & 3.67 \\
\hline Unstable decisions made & 3 & 15 & 7 & 35 & 10 & 50 & 3.52 \\
\hline The impact of other people on management decisions & 4 & 20 & 8 & 40 & 8 & 40 & 3.70 \\
\hline Unpleasant incidents for managers & 4 & 20 & 11 & 55 & 5 & 25 & 3.07 \\
\hline Showing too much partial views & 1 & 5 & 9 & 45 & 10 & 50 & 3.67 \\
\hline Spreading bad roomers & 6 & 30 & 6 & 30 & 8 & 40 & 3.15 \\
\hline Rejection of constructive suggestion by management & 1 & 5 & 7 & 35 & 12 & 60 & 3.80 \\
\hline No agreement for working performance & 3 & 15 & 6 & 30 & 11 & 55 & 3.60 \\
\hline Unfamiliarity of top managements with all responsibilities & 2 & 10 & 7 & 35 & 11 & 55 & 3.60 \\
\hline Unfamiliarity of top managements with their responsibilities & 0 & 0 & 6 & 30 & 14 & 70 & 4.02 \\
\hline Entrusting responsibilities & 0 & 0 & 5 & 25 & 15 & 75 & 4.12 \\
\hline The feeling of failure & 1 & 5 & 5 & 25 & 14 & 70 & 3.90 \\
\hline No agreement with group team & 0 & 0 & 4 & 20 & 16 & 80 & 4.20 \\
\hline Unfair executing laws & 1 & 5 & 6 & 30 & 13 & 65 & 3.90 \\
\hline $\begin{array}{l}\text { Unpleasant incidents for some employees who work in the } \\
\text { team }\end{array}$ & 1 & 30 & 6 & 30 & 8 & 40 & 3.15 \\
\hline The lack of a good trust among employees & 1 & 5 & 7 & 35 & 12 & 60 & 3.80 \\
\hline Discrimination on wage payment & 3 & 15 & 6 & 30 & 11 & 55 & 3.60 \\
\hline Unstable regularities & 3 & 15 & 6 & 30 & 11 & 55 & 3.60 \\
\hline Feeling of loosing position & 1 & 5 & 5 & 25 & 14 & 70 & 4.02 \\
\hline Feeling of having no promotion & 0 & 0 & 6 & 30 & 14 & 70 & 4.02 \\
\hline Unpleasant relationship with family partner & 0 & 0 & 5 & 25 & 15 & 75 & 4.12 \\
\hline Unpleasant relationship with children & 3 & 15 & 6 & 30 & 11 & 55 & 3.60 \\
\hline Chaos living conditions & 3 & 15 & 5 & 25 & 12 & 60 & 3.67 \\
\hline Having an ill family member & 4 & 20 & 7 & 35 & 9 & 45 & 3.37 \\
\hline
\end{tabular}


As we can observe from Table 2, the maximum weighted mean is 4.32 for discrimination on annual job compensation; the next maximum weighted mean is 4.12 , which is associated with entrusting responsibilities and unpleasant relationship with family partner. There are other important factors affecting working performance such as unpleasant working condition, lack of job promotion, no change on working conditions, discrimination on applying laws, etc. Next section, we examine the hypotheses associated with our proposed study.

\section{The results}

In this section, we present the results of our survey for examining different hypotheses. The first and the main question of the survey is as follows,

Q1. Can we improve work performance of employees by removing demotivating factors?

Table 3 shows the summary of our survey in terms of the average score, frequency, percentage and accumulated scores.

Table 3

Summary of the survey associated with the main question of the survey

\begin{tabular}{cccc}
\hline Average Score & Frequency & Percentage & Accumulated \\
\hline 2.10 & 1 & 5 & 5 \\
2.32 & 1 & 5 & 10 \\
2.85 & 2 & 10 & 20 \\
2.91 & 1 & 5 & 25 \\
2.95 & 2 & 10 & 35 \\
3.04 & 1 & 5 & 40 \\
3.24 & 1 & 5 & 45 \\
3.41 & 3 & 15 & 60 \\
3.52 & 2 & 10 & 70 \\
3.80 & 1 & 5 & 75 \\
3.92 & 1 & 5 & 80 \\
4.10 & 1 & 5 & 85 \\
4.12 & 1 & 5 & 90 \\
\hline
\end{tabular}

The average number is 3.25 with the standard deviation of 0.68 . As we can observe we can reach a valid t-student under 5\% significance level, which means the null hypothesis associated with the main question of our survey is rejected and we can conclude that removing the barriers could increase employees' motivations. The other question is that whether removing financial demotivating factors could increase employees' motivation and the responses are summarized in Table 4 as follows,

\section{Table 4}

The summary of survey on the effect of removing financial demotivating factors on employees' motivation

\begin{tabular}{cccc}
\hline Average score & Frequency & Percent & Accumulated \\
\hline 1.8 & 3 & 15 & 15 \\
2.1 & 2 & 10 & 25 \\
2.32 & 1 & 5 & 30 \\
2.70 & 2 & 10 & 40 \\
2.81 & 1 & 5 & 45 \\
2.95 & 2 & 10 & 55 \\
3.04 & 1 & 5 & 60 \\
3.24 & 1 & 5 & 65 \\
3.41 & 3 & 15 & 80 \\
3.52 & 2 & 10 & 90 \\
3.80 & 1 & 5 & 95 \\
3.92 & 1 & 5 & 100 \\
\hline
\end{tabular}


The average number is 2.04 with the standard deviation of 1.68 . As we can observe we can reach a valid t-student under 5\% significance level, which means the null hypothesis associated with the second question of our survey is rejected and we can conclude that removing financial barriers could increase employees' motivations. Another question is that whether removing non-financial demotivating factors could increase employees' motivation and the responses are summarized in Table 5 as follows,

Table 5

The summary of survey on the effect of removing non-financial demotivating factors on employees' motivation

\begin{tabular}{cccc}
\hline Average score & Frequency & Percent & Accumulated \\
\hline 2.01 & 2 & 10 & 10 \\
2.31 & 2 & 10 & 20 \\
2.90 & 1 & 5 & 25 \\
3.01 & 4 & 20 & 45 \\
3.25 & 3 & 15 & 60 \\
3.30 & 2 & 10 & 70 \\
3.81 & 1 & 5 & 75 \\
3.91 & 3 & 15 & 90 \\
4.20 & 2 & 10 & 100 \\
\hline
\end{tabular}

The average number is 3.32 with the standard deviation of 0.67 . As we can observe we can reach a valid t-student under 5\% significance level, which means the null hypothesis associated with the third question of our survey is rejected and we can conclude that removing non-financial barriers could increase employees' motivations. The last question is whether financial demotivating factors have more influence on employees' motivation compared with non-financial demotivating factors. Table 6 summarizes the summary of our survey.

Table 6

The influence of financial demotivating factors versus non-financial factors

\begin{tabular}{lccc}
\hline Item & Average & Standard deviation & t-student \\
\hline Non-Financial & 3.32 & 0.67 & 2.21 \\
Financial & 2.04 & 1.68 & \\
\hline
\end{tabular}

As we can observe from the results of Table 6, t-student is meaningful under 5\% significance level, which means the removing non-financial barriers could better increase employees' motivation than financial barriers. In summary, since the survey in performed in a country with more spirituality background, we can conclude that people do care about what is happening in their social working environment than other financial issues.

\section{Conclusion}

In this paper, we have studied various factors on demotivating workers using questionnaire consist of various questions. The questionnaire was distributed among some employees who worked for rubber production units located in Esfahan, Iran. The results of this survey indicated that discrimination on annual job compensation, entrusting responsibilities and unpleasant relationship with family partner are most important factors influencing employees' motivation. The survey also showed that while financial factors was important on increasing employees' motivation, non-financial factors are considered more important. 


\section{References}

Delfgaauw, J., \& Dur, R. (2007). Signaling and screening of workers' motivation. Journal of Economic Behavior \& Organization, 62(4), 605-624.

de Lange, A.H., Van Yperen, N.W., Van der Heijden B.I.J.M., \& Matthijs Bal, P. (2010). Dominant achievement goals of older workers and their relationship with motivation-related outcomes. Journal of Vocational Behavior, 77(1) 118-125.

Gällstedt, M. (2003). Working conditions in projects: perceptions of stress and motivation among project team members and project managers. International Journal of Project Management, 21(6), 449-455.

Linz, S.J. (2004). Motivating Russian workers: analysis of age and gender differences. Journal of Socio-Economics, 33(3), 261-289.

Likert, R. (1932). A Technique for the Measurement of Attitudes. Archive of Psychology, 140, 1-55.

Lan, L., Lian, Z., \& Pan, L. (2010).The effects of air temperature on office workers' well-being, workload and productivity-evaluated with subjective ratings. Applied Ergonomics, 42(1), 29-36.

Mak, B.L., \& Sockel, H. (2001). A confirmatory factor analysis of IS employee motivation and retention. Information \& Management, 38(5), 265-276.

Ng, S.T., Skitmore, R.M., Lam, K.C., \& Poon, A.W.C. (2004). Demotivating factors influencing the productivity of civil engineering projects. International Journal of Project Management, 22(2), 139-146.

Opsahl, R.L., \& Dunnette, M.D. (1996). Role of financial compensation in industrial motivation. Psychology Bulletin, 66(2), 94-118.

Tremblay, M.A., Blanchard, C.M., Taylor, S., Pelletier, L.G., \& Villeneuve, M. (2009). Work Extrinsic and Intrinsic Motivation Scale: Its Value for Organizational Psychology Research. Canadian Journal of Behavior Science, 41(4), 213-226.

Zakeri, M., Olomolaiye, P., Holt, G.D., \& Harris, F.C. (1997). Factors affecting the motivation of Iranian construction operatives. Building and Environment, 32(2), 161-166 